\title{
Diabetic ketoacidosis in children and adolescents
} with newly diagnosed type I diabetes in Tigray, Ethiopia: retrospective observational study

This article was published in the following Dove Press journal: Pediatric Health, Medicine and Therapeutics

Fikaden Berhe Hadgu' Gereziher Gebremedhin Sibhat ${ }^{2}$ Letekirstos GebreEgziabher Gebretsadik $^{3}$

'Department of Pediatrics and Child Health, College of Health Sciences, Mekelle University, Tigray, Ethiopia; ${ }^{2}$ Department of Pharmacognocy, School of Pharmacy, College of Health Sciences, Mekelle University, Tigray, Ethiopia; ${ }^{3}$ Department of Biostatistics, School of Public Health, College of Health Sciences, Mekelle University, Tigray, Ethiopia
Correspondence: Fikaden Berhe Hadgu Department of Pediatrics and Child Health, College of Health Sciences, Mekelle University, PO Box 187I Tigray, Ethiopia

Tel +25 I9I 474844 I

Email fikadenb@gmail.com
Background: Diabetic ketoacidosis (DKA) is the most severe acute complication of type 1 diabetes mellitus which results in increased risk of morbidity and mortality especially in developing countries.

Objective: To assess prevalence and associated factors of diabetic ketoacidosis in children and adolescents with newly diagnosed type 1 diabetes in hospitals of the Tigray region, Ethiopia.

Methods: A facility based retrospective observational study design was conducted in newly diagnosed type 1 diabetic children and adolescents up to the age of 18 years who were registered in 13 general and two referral hospitals from January 1, 2013 to December 30, 2017. The diagnosis of diabetic ketoacidosis was made with the criteria below, Children presenting with polysymptoms, weight loss, vomiting, dehydration, and also the indirect signs or effects of acidosis on respiratory and central nervous systems like Kussmaul breathing, lethargy or coma and biochemically random blood sugar level $>11 \mathrm{ml} / \mathrm{L}$, glucosuria and urine ketone $>+1$ and diagnosed with type 1 diabetes for the first time. Descriptive, Mann-Whitney $U$ and logistic regression analysis were carried out to describe and identify the associated factors with diabetic ketoacidosis.

Results: More than three-quarters, 258/328 (78.7\%) of the newly diagnosed type 1 diabetes patients, presented with diabetic ketoacidosis at initial diagnosis. Median age of diabetic ketoacidosis patients was 11 years. The patients with diabetic ketoacidosis were younger than nondiabetic ketoacidosis patients ( 11 vs 13 years, $P=0.002$ ). The mortality rate of diabetic ketoacidosis was $4.3 \%$. Young age, presence of precipitating factors and symptoms of DKA/ diabetes were found to be highly associated with diabetic ketoacidosis at initial diagnosis.

Conclusions: The prevalence of diabetic ketoacidosis was alarmingly high. Young age group patients, precipitating factors and the presence of symptoms of diabetes/DKA like excessive drinking, vomiting and fatigue were highly associated with diabetic ketoacidosis.

Keywords: prevalence, type 1diabetes, ketoacidosis, children, Tigray

\section{Introduction}

Diabetic ketoacidosis (DKA) is the most severe acute complication of type 1 diabetes mellitus, characterized by a biochemical triad of hyperglycemia, ketonemia (ketonuria) and acidemia. DKA is caused by a decrease or ineffective circulating insulin associated with elevations in counter regulatory hormones. ${ }^{1}$ According to International Society for Pediatric and Adolescent Diabetes (ISPAD) DKA is defined as random blood glucose level $>11 \mathrm{mmol} / \mathrm{L}$, venous $\mathrm{pH}<7.3$ or bicarbonate $<15 \mathrm{mmol} / \mathrm{L}$, ketonemia, and ketonuria. $^{2}$ 
Globally, more than 96,000 children and adolescents under 15 years of age are estimated to develop type 1 diabetes yearly and the number is estimated to be greater than 132,600 when the age extends to 20 years. ${ }^{3}$ Delayed diagnosis in newly diagnosed type 1 diabetes may lead to diabetic ketoacidosis. Previous studies showed that worldwide variation in the frequency of DKA at initial diagnosis of diabetes ranges from $12.8-80 \%{ }^{4}$

Diabetic ketoacidosis results in significant morbidity and mortality in children. Cerebral insult is the main cause of morbidity and mortality in children and cerebral edema accounts for $60-90 \%$ of all deaths from DKA. ${ }^{2}$ The mean medical expense with single admission of DKA in privately insured US children was over $\$ 3,500 .^{5}$

The prevalence of DKA in sub-Saharan Africa is not well known. However, there are a few studies from Africa that showed the frequency to vary from $80-88 \%{ }^{6}{ }^{6}$

Despite the high socioeconomic burden and high morbidity and mortality, the prevalence and risk factors of DKA in newly diagnosed children and adolescents is barely studied in Ethiopia. There are no reports on the prevalence and associated factors of DKA in newly diagnosed type 1 diabetic children and adolescents in the Tigray region until the study period. Therefore, the present study was aimed to assess prevalence and associated risk factors of DKA in children and adolescents in the Tigray region public hospitals.

\section{Patients and methods}

\section{Study design}

A facility based retrospective observational study design was conducted in children and adolescents with newly diagnosed type 1 diabetes in Tigray public hospitals from January 1, 2013 to December 30, 2017.

\section{Study setting}

This study was conducted in Tigray regional state, Ethiopia. Tigray is one of the nine regions in Ethiopia, located in the northernmost part of Ethiopia and covers an area of $53,638 \mathrm{~km}^{2}$. To the north, it borders the state of Eritrea, to the west with north Sudan, to the south and to the east it is bordered by the Amhara and Afar regions of Ethiopia respectively. The region has 13 general public hospitals, two referral hospitals, 20 primary hospitals, 204 health centers, and 712 health posts. According to a population projection of Ethiopia for all regions at wereda (district) level from 2014-2017 done by the Central Statistical Agency of Ethiopia, Tigray has a total population of $5,247,005 .^{7}$ The present study was conducted in 13 general and two referral hospitals.

\section{Exclusion}

Patients who were diagnosed and were on treatment in another health facility and came for follow-up, and if the transfer does not mention whether the patient presented with DKA or not at initial diagnosis of diabetes were excluded from the study.

\section{Sample size}

All pediatric and adolescents who were newly diagnosed with type 1 diabetes in the study period were included.

\section{Data collection procedures}

Prestructured data collection format was used to collect the data by trained professional nurses. In the checklist sociodemographic, clinical characteristics of DKA at diagnosis, outcome defined as improved or died and specific initial laboratory data were included. The diagnosis of DKA was made when the following diagnostic criteria were fulfilled. Children presenting with polysymptoms, weight loss, vomiting, dehydration, indirect signs or effects of acidosis on respiratory and central nervous systems like Kussmaul breathing, lethargy or coma and biochemically random blood sugar level $>11$, glucosuria and urine ketone $>+1$ and diagnosed with type 1 diabetes for the first time. Diagnosis of type 1 diabetes mellitus is made when there is symptoms of diabetes mellitus and random or casual plasma glucose $>11$ $\mathrm{mmol} / \mathrm{L}$ or $\geq 200 \mathrm{mg} / \mathrm{dL}$ or fasting (at least 8 hours) plasma glucose $\geq 126 \mathrm{mg} / \mathrm{dL}{ }^{2}$

\section{Operational definition}

Diabetic ketoacidos: children presenting with polysymptoms, weight loss, vomiting, dehydration, Kussmaul breathing, lethargy or coma and biochemically random blood sugar level $>11$, glucosuria and urine ketone $>+1$.

Infant: less than one year of age.

Children: one up to 10 years of age.

Adolescent: adolescent is defined as age 10.1 up to 18 years.

Random blood sugar level: blood sugar level taken at any time of a day.

Initial diagnosis: the time at which the individual is diagnosed with diabetes for the first time. 


\section{Statistical analysis}

Data were entered to SPSS version 16 (SPSS Inc., Chicago, IL, USA). The data were checked for outliers. Descriptive analysis was performed using frequency distribution, mean, median, nonparametric test (Mann-Whitney $\mathrm{U})$, tables and graph. Crude odds ratio and adjusted odds ratio (AOR) were computed at a $95 \% \mathrm{CI}$. Bivariate and multiple logistic regression analysis were carried out to identify the association between dependent and independent factors. Stepwise regression where variables with $P$-value $<0.25$ during bivariate analysis were included in the multiple logistic regression model. Finally variables with $P$-value $<0.05$ were expressed as associated factors of DKA.

\section{Ethical clearance}

Before data collection, Ethical clearance was obtained from Mekelle University, College of Health Sciences, Ethical Clearance Committee, and Tigray Regional Health Bureau. Data was taken from patient charts. Hence, confidentiality of data was kept and the data was not used for other purposes other than the purpose of this study. Patient consent was not needed for this (retrospective) study, as the college reserves the right to own the medical records of patients.

\section{Results}

During the study period a total of 360 type 1 diabetic children and adolescents were seen in the study hospitals. Of these, 32 patients were excluded from the study where 10 of them had incomplete charts and 14 patients transferred from other health facilities for follow-up, as a result, it was not possible to know whether their initial presentation was DKA or not. In addition, there were lost charts for 8 patients. Hence, 328 newly diagnosed type 1 diabetes patients were included in this study where 258/328 (78.7\%) of them presented in diabetic ketoacidosis at diagnosis of type 1 diabetes (Figure 1).

The age of DKA patients ranges between 3 months and 18 years. Only $5(1.93 \%)$ were less than one year of age and all of them presented with DKA, while 133/258 $(51.6 \%)$ were 10.1 up to 18 years. The median age at presentation of DKA patients was 11 years (IQR: 7-14) however, the median age at presentation of non DKA patients was 13 years (IQR: 10-15) (Figure 2).

DKA patients were younger than non DKA (11 vs 13 years, $P=0.002)$. Of the 328 newly diagnosed type 1 diabetes children and adolescents at the primary diagnosis, more than half, 174 (53.1\%) were male. From 258 of DKA patients $143(55.4 \%)$ were male. Male to female ratio of DKA patients was 1.24:1.

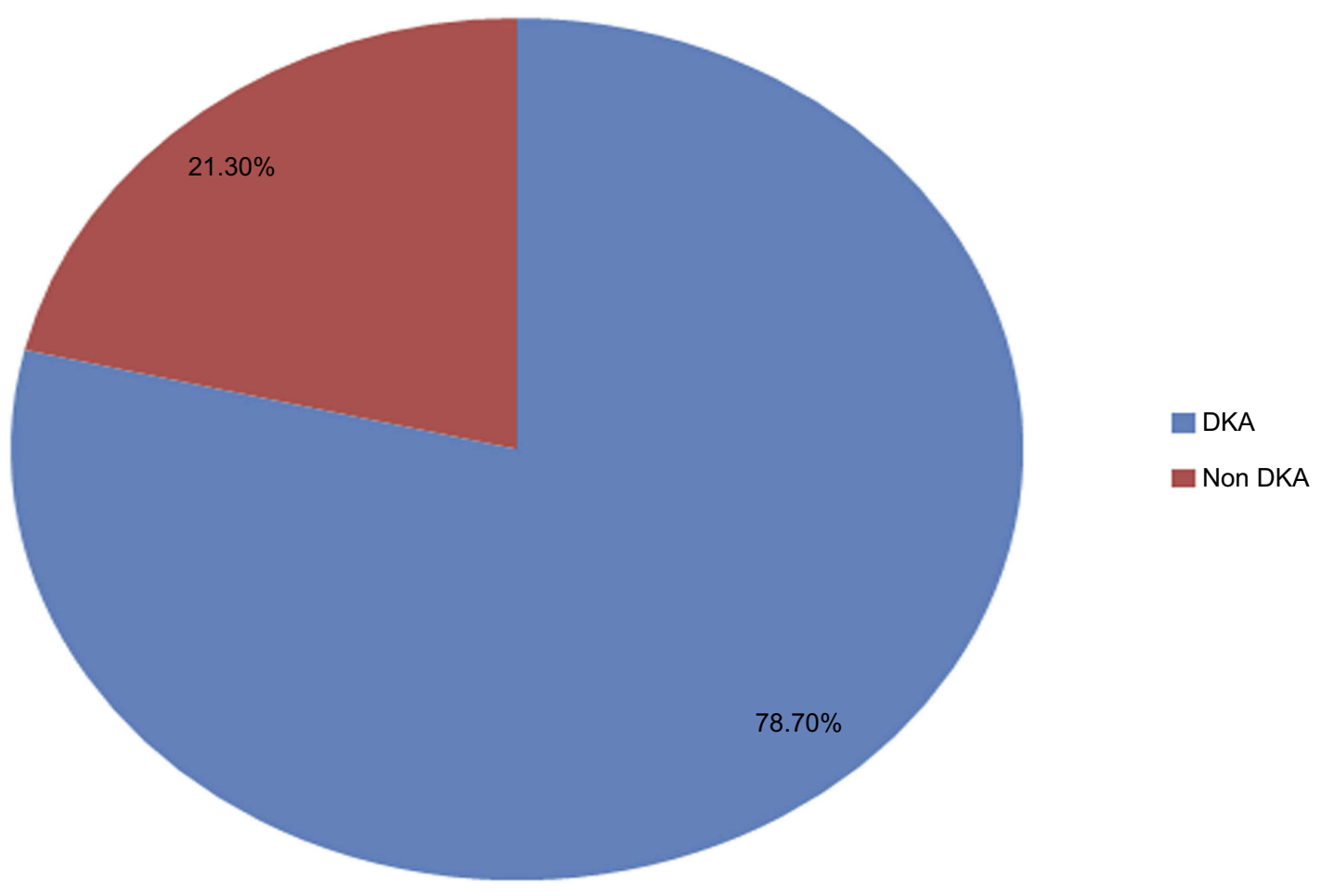

Figure I Prevalence of DKA and non DKA in newly diagnosed type I diabetes mellitus in hospitals of Tigray. Abbreviation: DKA, diabetic ketoacidosis. 


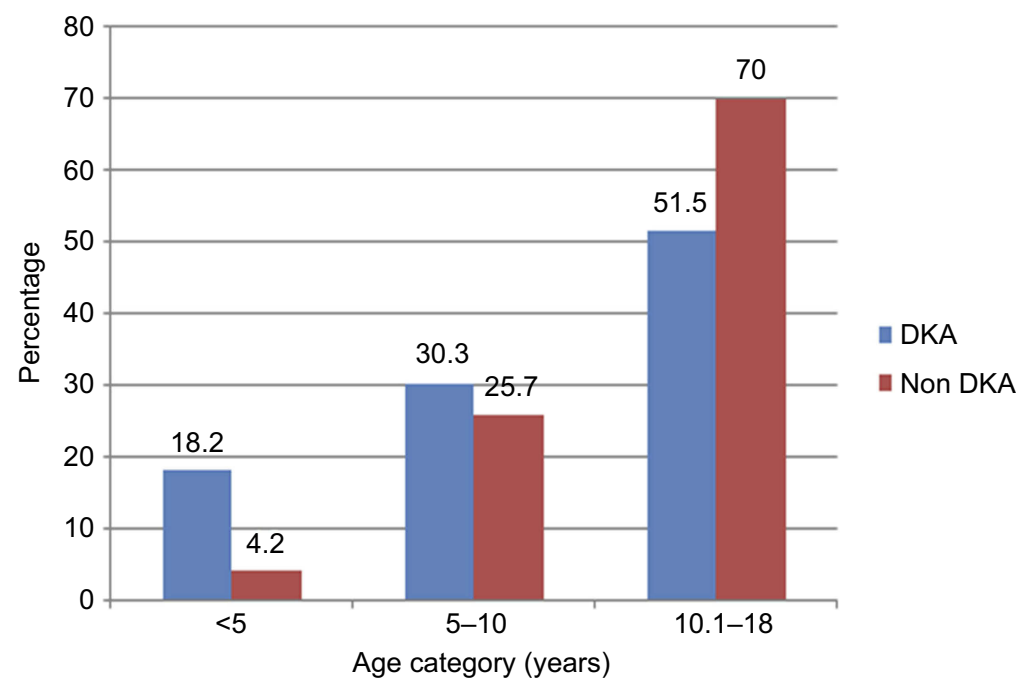

Figure 2 Comparison between age group of DKA and non DKA patients. Abbreviation: DKA, diabetic ketoacidosis.

Table I Sociodemographic characteristics of DKA in newly diagnosed patients in Tigray hospitals, Northern Ethiopia

\begin{tabular}{|c|c|c|}
\hline Factor & $\begin{array}{l}\text { DKA } \\
N=258\end{array}$ & $\begin{array}{l}\text { Non DKA } \\
\mathbf{N}=70\end{array}$ \\
\hline \multicolumn{3}{|c|}{ IAge at presentation } \\
\hline Median & II years (IQR: 7-I4) & 13 years (IQR: 10-15) \\
\hline \multicolumn{3}{|l|}{ Sex } \\
\hline Female (\%) & $115(44.6)$ & $34(48.6)$ \\
\hline Male (\%) & $143(55.4)$ & $36(5 \mid .4)$ \\
\hline \multicolumn{3}{|l|}{ Residence } \\
\hline Urban (\%) & $98(38)$ & $20(28.6)$ \\
\hline Rural (\%) & $160(62)$ & $50(71.4)$ \\
\hline \multicolumn{3}{|c|}{ Family history of diabetes } \\
\hline No (\%) & 198 (77.7) & $49(70)$ \\
\hline Yes (\%) & $60(23.3)$ & $21(30)$ \\
\hline
\end{tabular}

Abbreviation: DKA, diabetic ketoacidosis.

First-degree family history of type 1 diabetes was positive in $60(23.3 \%)$ of the DKA patients. From these, siblings accounts for $45(75 \%)$, fathers $7(11.7 \%)$ and mothers 8 (13.3\%) (Table 1).

The minimum duration of symptom was 24 hours and the maximum was 90 days. The median duration of symptoms before presentation of DKA was 10 days (IQR: 7-21). Poly symptoms (polyuria (92\%), polydipsia (93\%) and weight loss (48\%) were the leading causes of presentation (Table 2 ).

The mean RBS level of DKA patients was $465 \pm 122 \mathrm{mg} /$ dL. About $35 \%$ of DKA patients had infections as
Table 2 Presenting symptoms and signs of patients with DKA

\begin{tabular}{|l|l|l|}
\hline & \multicolumn{2}{|l|}{ DKA (N=258) } \\
\hline Symptom and signs & Number & Percent \\
Polydipsia & 240 & 93 \\
Polyuria & 239 & 92.6 \\
Polyphagia & 138 & 53 \\
Vomiting & 113 & 44 \\
Weight loss & 123 & 47.6 \\
Fatigue & 199 & 77 \\
Lethargy & 80 & 31 \\
Abdominal pain & 58 & 22.5 \\
Fast breathing & 61 & 23.6 \\
Kussmaul breathing & 47 & 18.2 \\
Fever & 46 & 17.8 \\
Headache & 31 & 12 \\
Comatous & 21 & 8 \\
\hline
\end{tabular}

Abbreviation: DKA, diabetic ketoacidosis.

a precipitating factor while trauma accounted for about $2 \%$. However, in the majority of them $(62.5 \%)$, there was no identified precipitating factor (Table 3 ). In this study there were 11 deaths of DKA patients which makes the case fatality rate of DKA $4.3 \%$. Out of which 6 patients died of cerebral edema, while another 3 died of sepsis. However, in 2 patients the cause of death was not recorded.

On bivariate logistic regression, age, residency, family history of type 1 diabetes, vomiting, fatigue, excessive drinking, excessive urination and precipitating factors showed significant association with DKA at initial diagnosis. However, on multiple regression analysis age, 
Table 3 Precipitating factors in newly diagnosed DKA children and adolescents

\begin{tabular}{|l|l|l|l|}
\hline Factor & & Number & Percent \\
\hline Infection & Pneumonia & 41 & 15.9 \\
& URTI & 31 & 12 \\
& UTI & 13 & 5 \\
& Meningitis & 4 & 1.5 \\
Trauma & Malaria & 2 & 0.8 \\
\hline No precipitating factor identified & Physical & 6 & 2.3 \\
\hline
\end{tabular}

Abbreviations: DKA, diabetic ketoacidosis; UTRI, upper respiratory tract infection; UTI, urinary tract infection.

vomiting, fatigue, excessive drinking and the presence of precipitating factor were found to be highly associated with DKA at initial diagnosis of diabetes mellitus (Table 4).

The odds of developing DKA in children with newly diagnosed diabetes aged 5-10 years and 10.1-18 years were $76 \%$ and $86 \%$ lowered compared to less than 5 years old respectively. The odds of developing DKA in newly diagnosed diabetes was $7.81(\mathrm{AOR}=7.81,95 \% \mathrm{CI}$ : 2.99-20.90, $P<0.001)$ times higher in children who had a precipitating factor at the diagnosis of diabetes than those who did not have precipitating factors.

\section{Discussion}

According to the current study almost $80 \%$ of newly diagnosed type 1 diabetes patients initially presented with DKA. This alarmingly high number implies that the study populations' level of awareness of the symptoms of diabetes is very low.

A study conducted in a referral hospital Addis Ababa, Ethiopia showed the similar prevalence of DKA to be $80 \% .{ }^{8}$ However, a recent report which was done after 10 years in Addis Ababa, Ethiopia by Atkilt et al showed a prevalence of $35.8 \% .^{9}$ The lower prevalence from this study could be explained the fact that the study was done in Addis Ababa which is the capital city of Ethiopia where parents and other care takers may have better awareness about signs and symptoms of diabetes/ DKA. Moreover, there are similar studies from Africa viz, $77.1 \%$ in Nigeria, ${ }^{10}$ Tanzania and Congo $(90 \%) .{ }^{11}$ A systematic review on the variation between countries in the frequency of DKA at first presentation showed that the frequency ranged from $12.8-80 \%$, with highest frequencies in the United Arab Emirates, Saudi Arabia and Romania, and the lowest in Sweden, the Slovak Republic and Canada, ${ }^{4}$ all showing the well-known wide geographic variation in prevalence of DKA at the onset of diabetes mellitus in children. Variation in the

Table 4 Bivariate and multiplelogistic regression analysis of DKA and non DKA patients

\begin{tabular}{|c|c|c|c|c|c|}
\hline \multicolumn{2}{|l|}{ Variable } & \multirow{2}{*}{$\begin{array}{l}\text { DKA, N=258 } \\
47 \\
78 \\
133\end{array}$} & \multirow{2}{*}{$\begin{array}{l}\text { Non DKA, N=70 } \\
3 \\
18 \\
49\end{array}$} & \multirow{2}{*}{$\begin{array}{l}\text { AOR (95\%Cl) } \\
\text { Ref. } \\
0.24(0.06-0.95) \\
0.14(0.04-0.51)\end{array}$} & \multirow{2}{*}{$\begin{array}{l}P \text {-value } \\
0.042 \\
0.003\end{array}$} \\
\hline Age & $\begin{array}{l}<5 \\
5-10 \\
10.1-18\end{array}$ & & & & \\
\hline Residence & $\begin{array}{l}\text { Rural } \\
\text { Urban }\end{array}$ & $\begin{array}{l}160 \\
98\end{array}$ & $\begin{array}{l}50 \\
20\end{array}$ & $\begin{array}{l}\text { Ref. } \\
\text { I.40 (0.37-I.35) }\end{array}$ & 0.300 \\
\hline Family history of diabetes & $\begin{array}{l}\text { No } \\
\text { Yes }\end{array}$ & $\begin{array}{l}198 \\
60\end{array}$ & $\begin{array}{l}49 \\
21\end{array}$ & $\begin{array}{l}\text { Ref. } \\
0.60(0.30-\mid .21)\end{array}$ & 0.16 \\
\hline Excessive drinking & $\begin{array}{l}\text { No } \\
\text { Yes }\end{array}$ & $\begin{array}{l}18 \\
240\end{array}$ & $\begin{array}{l}12 \\
58\end{array}$ & $\begin{array}{l}\text { Ref. } \\
6.60(1.98-22.00)\end{array}$ & 0.002 \\
\hline Excessive urination & $\begin{array}{l}\text { No } \\
\text { Yes }\end{array}$ & $\begin{array}{l}19 \\
239\end{array}$ & $\begin{array}{l}11 \\
59\end{array}$ & $\begin{array}{l}\text { Ref } \\
\text { I.22 (0.38-3.86) }\end{array}$ & 0.74 \\
\hline Vomiting & $\begin{array}{l}\text { No } \\
\text { Yes }\end{array}$ & $\begin{array}{l}156 \\
102\end{array}$ & $\begin{array}{l}58 \\
12\end{array}$ & $\begin{array}{l}\text { Ref. } \\
2.73(1.29-5.80)\end{array}$ & 0.009 \\
\hline Fatigue & $\begin{array}{l}\text { No } \\
\text { Yes }\end{array}$ & $\begin{array}{l}146 \\
112\end{array}$ & $\begin{array}{l}50 \\
20\end{array}$ & $\begin{array}{l}\text { Ref. } \\
2.22(1.17-4.22)\end{array}$ & 0.015 \\
\hline Precipitating factor & $\begin{array}{l}\text { No } \\
\text { Yes }\end{array}$ & $\begin{array}{l}166 \\
92\end{array}$ & $\begin{array}{l}63 \\
7\end{array}$ & $\begin{array}{l}\text { Ref. } \\
7.8 \mathrm{I}(2.97-20.50)\end{array}$ & $<0.001$ \\
\hline
\end{tabular}

Abbreviations: DKA, diabetic ketoacidosis; AOR, adjusted OR. 
study population may explain the difference in prevalence, the incidence of diabetes in the study population, the presence or absence of family history of type 1 diabetes mellitus, socioeconomic status, the timing of diagnosis and treatment, and also on the definition of DKA used in the specific study. ${ }^{12}$

The median age at initial diagnosis of DKA in this study was 11 years which is in agreement with the studies conducted in Saudi Arabia, ${ }^{13}$ and Nigeria. ${ }^{10}$ Regarding the median age at initial diagnosis of DKA and non DKA, it was significantly lower in DKA patients, as it was also reported by other studies. ${ }^{10,14,15}$ Moreover, this study found that almost all the children under 5 years of age presented with DKA at initial diagnosis of type 1 diabetes. This is supported by similar studies. ${ }^{2,14,16,17}$ The reason could be due to difficulty in recognizing excessive urination in toddlers who are in diapers and difficulty of the young age group to ask for water. A systematic review by Smith et $\mathrm{al}^{16}$ revealed the reason for the high association of younger age and DKA may be multifactorial. Healthcare providers may have a lack of knowledge about the signs and symptoms of diabetes in younger ages and the classic symptoms may not be obvious and difficult to differentiate from acute common infections, in addition beta cell destruction may be more rapid at this age. This pattern is changing for the better in countries like Finland, as a result of strong awareness creation campaigns resulting in early diagnosis with mild metabolic deterioration in the younger age-group. ${ }^{18}$

The present study showed that the odds of children who have precipitating factors at initial diagnosis of type 1 diabetes were 7.81 times higher than those who did not have precipitating factors at diagnosis of DKA. This could be due to infection-caused inflammation, proinflammatory cytokine release, and counter-regulatory hormones that lead to insulin resistance and metabolic deterioration. ${ }^{16}$ The mortality rate of newly diagnosed type 1 diabetes with DKA was $4.3 \%$. In more than $50 \%$ of the patients who died, cerebral edema was cited as cause of death. The mortality rate is higher compared with the global mortality rate which is $0.3-1 \%$ of the patients. ${ }^{19}$ This could be due to delayed diagnosis and lack of best setups and/or inadequate knowledge and skill of health-care providers.

As this study has given us a view that the prevalence of DKA is high and that there is significant mortality, creating awareness in the population and in health-care providers is mandatory.

\section{Limitations of the study}

This study had significant limitations since it is a retrospective study, there were lost charts and significant numbers of incomplete medical records regarding early feeding patterns, family income and parental education as a result it was difficult to study the effects of these parameters on DKA.

- The definition used for DKA in this study was not according to ISPAD guidelines

- Moreover, as a cross-sectional study design this study does not show cause-and-effect relationships

\section{Conclusion}

In conclusion, the study revealed substantially high prevalence of diabetic ketoacidosis in children and adolescents with newly diagnosed type 1 diabetes mellitus. Diabetic ketoacidosis was highly associated with young age and the presence of precipitating factor and the symptoms that clinically predict the diagnosis of diabetes/DKA. This high prevalence calls for public awareness creation campaigns on signs and symptoms of diabetes mellitus to detect those who are at risk of developing diabetic ketoacidosis.

\section{Acknowledgment}

The authors are grateful to the staff in the medical records of the study hospitals for their assistance in retrieving the medical records of the patients.

\section{Disclosure}

The authors report no conflicts of interest in this work.

\section{References}

1. Norris AW, Wolfsdorf JI. Diabetes mellitus. In: Brook CGD, Clayton PE, Brown RS, editors. Brooks' Clinical Pediatric Endocrinology. 5th ed. Oxford: Blackwell Publishing Ltd; 2005:436-473.

2. Wolfsdorf JI, Allgrove J, Craig ME, et al. ISPAD clinical practice consensus guidelines 2014 compendium. Diabeticketoacidosis and hyperglycemic hyperosmolar state. Pediatr Diabetes. 2014;15(Suppl. 20):154-179. doi:10.1111/pedi.12103

3. International Diabetes Federation. Eighth edition, IDF Diabetes Atlas. Abu Dhabi: International Diabetes Federation; 2017.

4. Usher Smith JA, Thompson MJ, Ercole A, Walter FM. Variation between countries in the frequency of diabetic ketoacidosis at first presentation of type 1 diabetes in children: a systematic review. Diabetologia. 2012;55:2878-2894. doi:10.1007/s00125-012-2690-2

5. Shrestha SS, Zhang P, Barker L, Imperatore G. Medical expenditures associated with diabetes acute complications in privately insuredU.S. youth. DiabetesCare. 2010;33(12):2617-2622.

6. Monabeka HG, Mbika-Cardorelle A, Moyen G. Ketoacidosis in children and teenagers in Congo. Sante. 2003;13:139-141. 
7. Federal Democratic Republic of Ethiopia, Central Statistical Agency, Population Projection of Ethiopia for all-regions at Wereda Level from 2014-2017. Addis Ababa, Ethiopia. August 2013.

8. Fantahun B, Gedlu E. Prevalence of diabetic ketoacidosis in newly diagnosed diabetes mellitus pediatric patients in TikurAnbessa Specialized Hospital. Off Organ Ethiopian Pediatr Soc. 2008;4:1.

9. Atkilt HS, Turago MG, Tegegne BS. Clinical characteristics of diabetic ketoacidosis in children with newly diagnosed type 1 diabetes in Ethiopia. A cross-sectional study. PLoS One. 2017;12(1). doi:10.1371/journal.pone.0169666

10. Onyiriuka AN, Ifebi E. Ketoacidosis at diagnosis of type 1 diabetes in children and adolescents: frequency and clinical characteristics. J Diabetes Metab Disord. 2013;12(47):3-5. doi:10.1186/2251-6581$12-47$

11. Majaliwa ES, Munubhi E, Ramaiya K, et al. Survey on acute and chronic complications in children and adolescents with type 1 diabetes at Muhimbili National Hospital in Dares Salaam, Tanzania Diabetes Care. 2007;10(9):2187-2192. doi:10.2337/dc07-0594

12. Mbugua PK, Otieno CF, Kayima JK, Amayo AA, McLigeyo SO. Diabetic ketoacidosis: clinical presentation and precipitating factors at Kenyatta National Hospital, Nairobi. East Afri Med J. 2005;82 (suppl12):191-196.
13. Naeem MA, Al-Alem HA, Al-Dubayee MS, et al. Characteristics of pediatric diabetic ketoacidosis patients in Saudi Arabia. Saudi Med J. 2015;36(1):20-25. doi:10.15537/smj.2015.1.9763

14. Reddy Y, Ganie Y, Pillay K. Characteristics of children presenting with newly diagnosed type 1 diabetes. S Afr J Chem. 2013;7 (2):46-48. doi:10.7196/sajch.500

15. Razavi Z. Frequency of ketoacidosis in newly diagnosed type 1 Diabetic Children. Omj. 2010;25:114-117. doi:10.5001/omj.2010.31

16. Usher-Smith JA, Thompson MJ, Sharp SJ, Walter FM. Factors associated with the presence of diabetic ketoacidosis at diagnosis of diabetes in children and young adults: a systematic review. BMJ. 2011;343:d4092. doi:10.1136/bmj.d4092

17. Jefferies C, Cutfield SW, Derraik JG, et al. Fifteen-year incidence of diabetic ketoacidosis at onset of type 1 diabetes in children from a regional setting (Auckland,NewZealand). Sci Rep. 2015;5:10358. Available from: http://www.nature.com/scientic

18. Hekkala A, Knip M, Veijola R. Ketoacidosis at diagnosis of type 1 diabetes in children in Northern Finland: temporary changes over 20 years. Diabetes Care. 2007;30:861-866. doi:10.2337/dc07-0717

19. Edge JA, Hawkins MM, Winter DL, Dunger DB. The risk and outcome of cerebral oedema developing during diabetic ketoacidosis. Arch Dis Child. 2001;85:16-22. doi:10.1136/adc.85.1.16
Pediatric Health, Medicine and Therapeutics

\section{Publish your work in this journal}

Pediatric Health, Medicine and Therapeutics is an international, peerreviewed, open access journal publishing original research, reports, editorials, reviews and commentaries. All aspects of health maintenance, preventative measures and disease treatment interventions are addressed within the journal. Practitioners from all disciplines are

\section{Dovepress}

invited to submit their work as well as healthcare researchers and patient support groups. The manuscript management system is completely online and includes a very quick and fair peer-review system. Visit http://www.dovepress.com/testimonials.php to read real quotes from published authors. 